\title{
Brachial plexus injury after shoulder dislocation: a literature review
}

\author{
${\text { Olga Gutkowska }{ }^{1} \text { (D) Jacek Martynkiewicz }{ }^{1} \cdot \text { Maciej Urban }^{1} \cdot \text { Jerzy Gosk }}^{1}$
}

Received: 28 March 2018 / Revised: 17 May 2018 / Accepted: 21 June 2018 / Published online: 30 June 2018

(C) The Author(s) 2018

\begin{abstract}
Brachial plexus injuries are among the rarest but at the same time the most severe complications of shoulder dislocation. The symptoms range from transient weakening or tingling sensation of the upper limb to total permanent paralysis of the limb associated with chronic pain and disability. Conflicting opinions exist as to whether these injuries should be treated operatively and if so when surgery should be performed. In this review, available literature dedicated to neurological complications of shoulder dislocation has been analysed and management algorithm has been proposed. Neurological complications were found in 5.4-55\% of all dislocations, with the two most commonly affected patient groups being elderly women sustaining dislocation as a result of a simple fall and young men after high-energy injuries, often multitrauma victims. Infraclavicular part of the brachial plexus was most often affected. Neurapraxia or axonotmesis predominated, and complete nerve disruption was observed in less than $3 \%$ of the patients. Shoulder dislocation caused injury to multiple nerves more often than mononeuropathies. The axillary nerve was most commonly affected, both as a single nerve and in combination with other nerves. Older patient age, higher energy of the initial trauma and longer period from dislocation to its reduction have been postulated as risk factors. Brachial plexus injury resolved spontaneously in the majority of the patients. Operative treatment was required in 13-18\% of the patients in different studies. Patients with suspected neurological complications require systematic control. Surgery should be performed within 36 months from the injury when no signs of recovery are present.
\end{abstract}

Keywords Brachial plexus injury $\cdot$ Infraclavicular brachial plexus $\cdot$ Nerve injury $\cdot$ Shoulder dislocation · Glenohumeral dislocation $\cdot$ Terrible triad of the shoulder

\section{Introduction}

Traumatic anterior shoulder dislocation is the most common major joint dislocation with the incidence estimated at $2 \%$ of the population during lifetime [1,2]. It is connected with a high number of associated injuries, resulting both from the mechanism of the initial trauma and reduction techniques $[3,4]$. These

Olga Gutkowska

gutkowska.olga@gmail.com

Jacek Martynkiewicz

jacek.martynkiewicz@gmail.com

Maciej Urban

maciejurban@poczta.onet.pl

Jerzy Gosk

chiruraz@umed.wroc.pl

1 Department of Traumatology, Clinical Department of Traumatology and Hand Surgery, Wroclaw Medical University, ul. Borowska 213, 50-556 Wroclaw, Poland injuries can affect sole or multiple tendinous, neural and vascular structures around the shoulder joint. Neurological complications resulting from shoulder dislocation include single nerve injuries, as well as more complex brachial plexus injuries (BPIs) and can cause a wide scale of disability, ranging from transient weakening of the upper limb and tingling sensation to total permanent paralysis of the limb associated with chronic pain and secondary deformities causing psychological distress.

The purpose of this work is to evaluate the incidence of neurological injuries in patients who suffered shoulder dislocation, determine which nerve(s) are affected most often and what the mechanism and severity of nerve injuries are, what type of patients are most susceptible to neurological complications and with what other injuries can nerve injury coexist. We also aim to determine how long the recovery of limb function lasts in patients treated conservatively and operatively, what percentage of patients require operative treatment and what the optimal time frame for surgical intervention is. On the basis of literature data, we aim to create a management algorithm for patients with suspected neurological injury after shoulder dislocation. 


\section{Materials and methods}

A review of studies dedicated to neurological complications of traumatic anterior shoulder dislocation was performed. Search of keywords "glenohumeral dislocation", "shoulder dislocation", "brachial plexus injury", "nerve injury", "axillary nerve injury", "neurovascular injury", "infraclavicular lesions", "unhappy triad of the shoulder" and "terrible triad of the shoulder" in PubMed, MEDLINE, Scopus and Google Scholar databases from their inceptions to 28 February 2018 was conducted. Articles written in all languages, including case reports presenting single or combined neurological complications of shoulder dislocation, were included. Articles failing to report the cause of brachial plexus lesion, abstracts and duplicates were excluded. The summary of the analysed literature has been presented in Tables 1 and 2 .

This research received approval from Local Bioethics Committee of Wroclaw Medical University and was approved by the institution at which it was carried out.

\section{Incidence}

The earliest known description of brachial plexus lesion as a result of shoulder dislocation comes from 1910 [43]. According to historical publications dating back to $1930 \mathrm{~s}-$ 1950 s, injury to the axillary nerve was found in 5-60\% of patients after shoulder dislocation [3, 44-46]. The incidence of neurological complications is similar in the current literature and varies from 5.4 to $55 \%$, being more common in primary than in recurrent dislocations (10 and 2\%, respectively, according to McLaughlin and McLellan) [5, 10, 11, 13-16, $24,29,46-52]$. In the largest prospective study conducted on 3633 patients who suffered shoulder dislocation, the incidence of neurological deficit was $13.5 \%$ [5]. Brachial plexus injury was found in $1.2 \%$ of multitrauma patients in the study by Midha et al., with shoulder dislocation being responsible for $7 \%$ of closed BPIs [53]. Males predominated in all large patient groups $(\mathrm{M} / \mathrm{F}$ from 1.3:1 in the study by Robinson et al. to 6.3:1 among the patients studied by Fox et al.) (Table 1) [5, 18-22].

BPI after shoulder dislocation is most commonly observed in two patient groups. The first one comprises patients in whom dislocation is a result of high-energy forces (usually motor vehicle accident, rarer fall from a height or sports injury). In those patients, often being multitrauma victims, multiple other injuries coexist, including fractures of the shoulder girdle, proximal humerus and the first rib, which constitute separate possible causes of injury to the brachial plexus. In the analysed literature, high-energy injury was the cause of shoulder dislocation complicated with BPI in $18-71 \%$ of the patients in different studies $[5,6,8,9,12,18,19,22,51]$. In four studies analysing the largest patient groups, high-energy injury was responsible for $36-43 \%$ of the cases $[5,18,19,22]$.

The other group consists of patients who sustain shoulder dislocation as a result of a simple fall. The mean patient age in this group is higher (usually over 50 years), there are typically no accompanying fractures (fracture of the greater tuberosity of humerus (GTF) can be present) and nerve injury more often has transient character $[5,19,22]$. Analysis of the literature revealed simple fall to be the most common cause of BPI after shoulder dislocation (18-86\% of the patients in different studies), including $43-67 \%$ in the four studies on the largest patient groups $[5,18,19,22]$.

The mean age of the patients in the analysed groups varied from 30 years (Wehbe et al.) to 67 years (Stenning et al.) and in $64 \%$ of the groups it was above 50 years (Table 1) [7, 54].

\section{Mechanism of nerve injury}

Shoulder dislocation can cause damage to the neighbouring neural structures in several different mechanisms. Historical data reported two possible mechanisms of injury to the axillary nerve during shoulder dislocation. McGregor postulated that the nerve was damaged due to being crushed between the humeral head and the axillary border of the scapula [55]. Most authors, however, believed that the lesion resulted from traction injury, raising rapid recovery and predominance of motor over sensory injury as arguments to support this thesis $[56,57]$. Stevens provided the first description of this injury mechanism in 1934, stating that axillary nerve is stretched across the humeral head in the abducted and externally rotated position of the arm [57].

Two other confirmed mechanisms of nerve injury after shoulder dislocation are connected with accompanying damage to vascular structures. In such cases, symptoms of nerve injury occur tardily $[58,59]$. Formation of an expanding haematoma in the axillary region, close to the neural structures, causes compression and stretching of neural elements in the initial days and weeks after trauma and leads to scarring of the surrounding tissues and formation of adhesions further compressing elements of the brachial plexus [6-8, 38, 41, $58,60,61]$. Rarer, vascular injury may lead to formation of pseudoaneurysm or false aneurysm of the axillary artery which causes delayed compression of neural structures, characterised by unaltered limb function immediately after dislocation, with its gradual deterioration over the following days to months $[18,62,63]$.

The least information can be found about the fourth mechanism - injury to vasa nervorum causing ischaemia of peripheral nerves resulting in impairment of their function [54]. Insufficiency of vasa nervorum may result from both direct injury to the arterioles, which are especially susceptible to compression, and from injury to a major vessel [54]. 


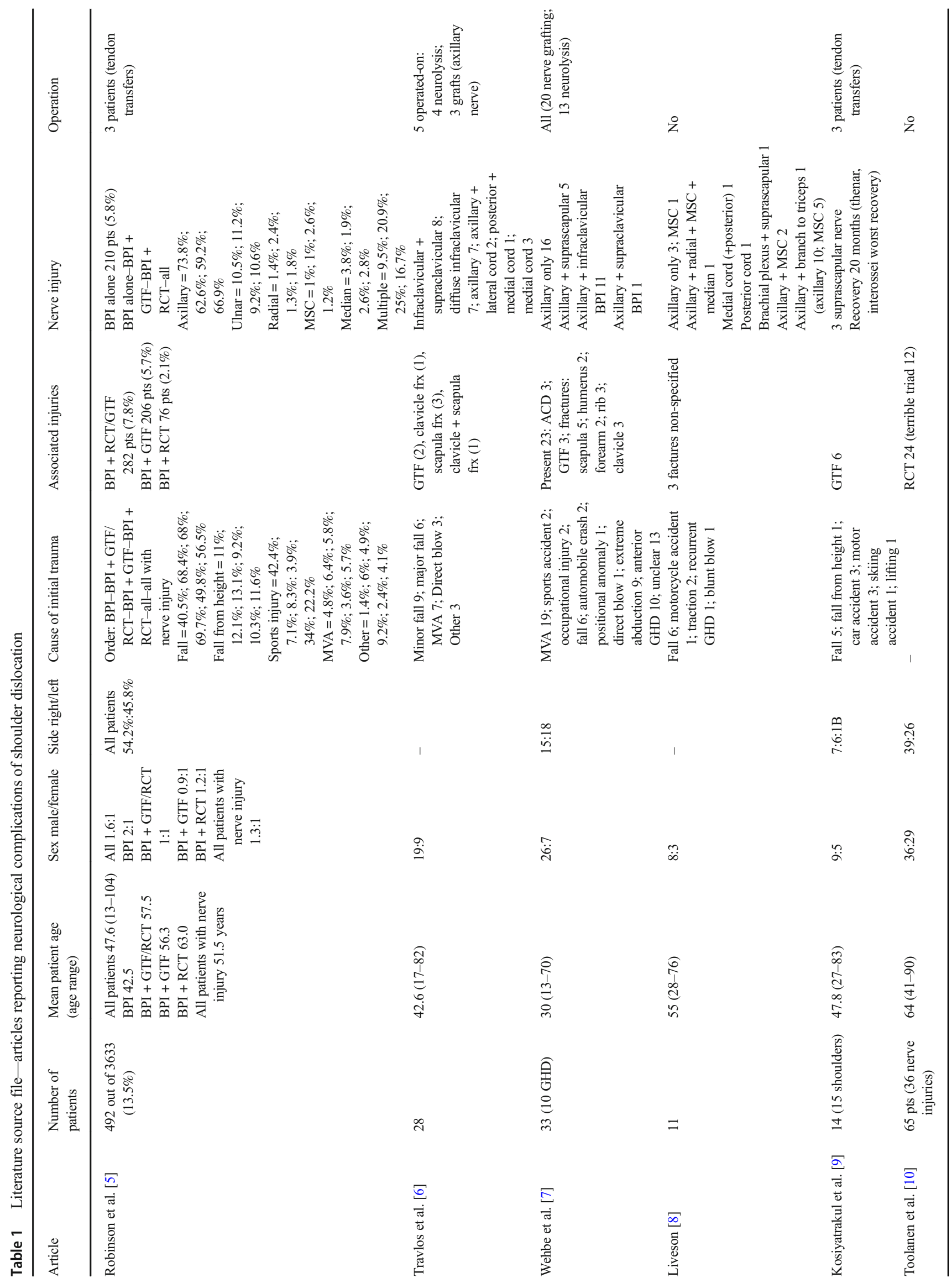




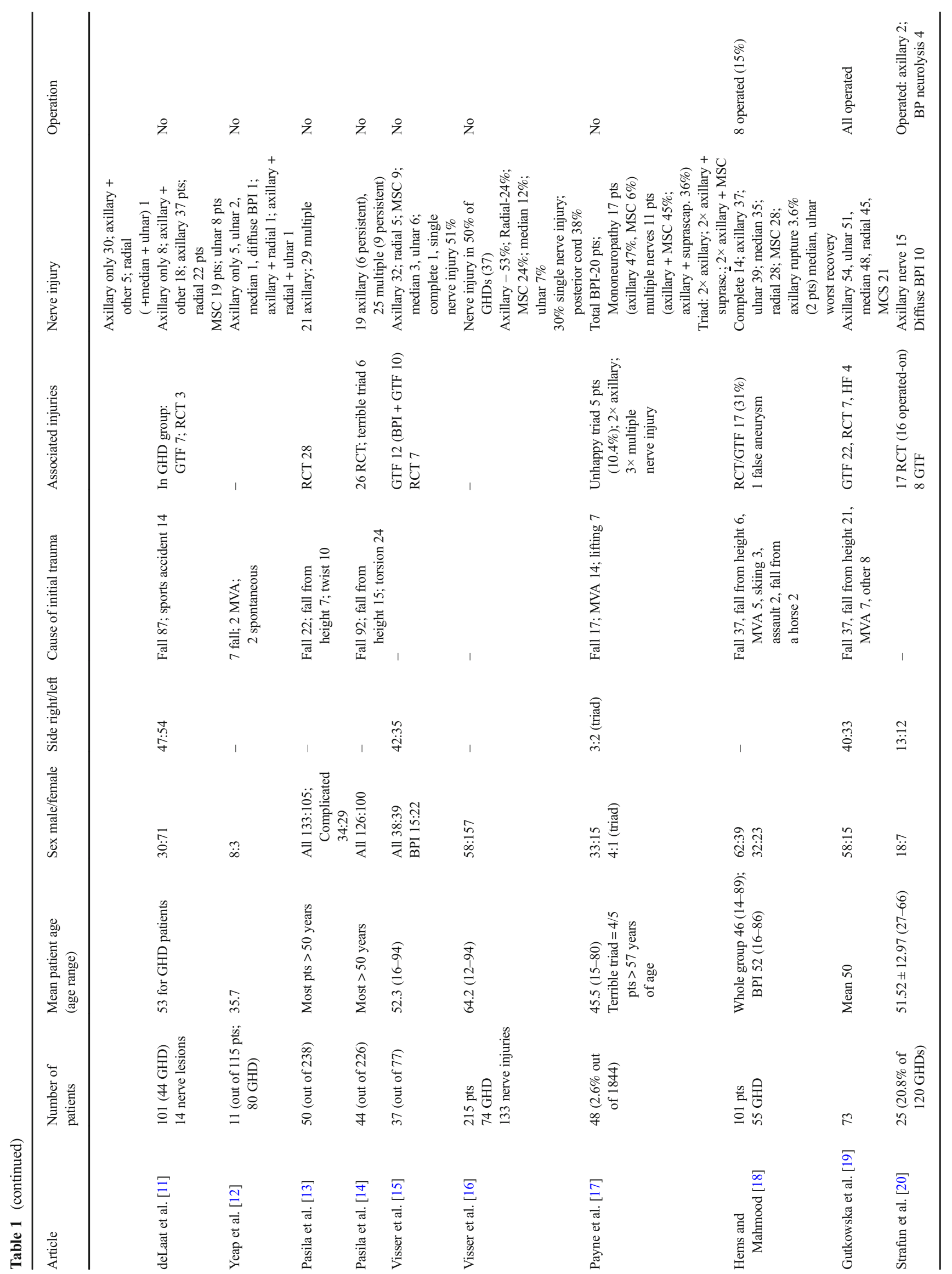




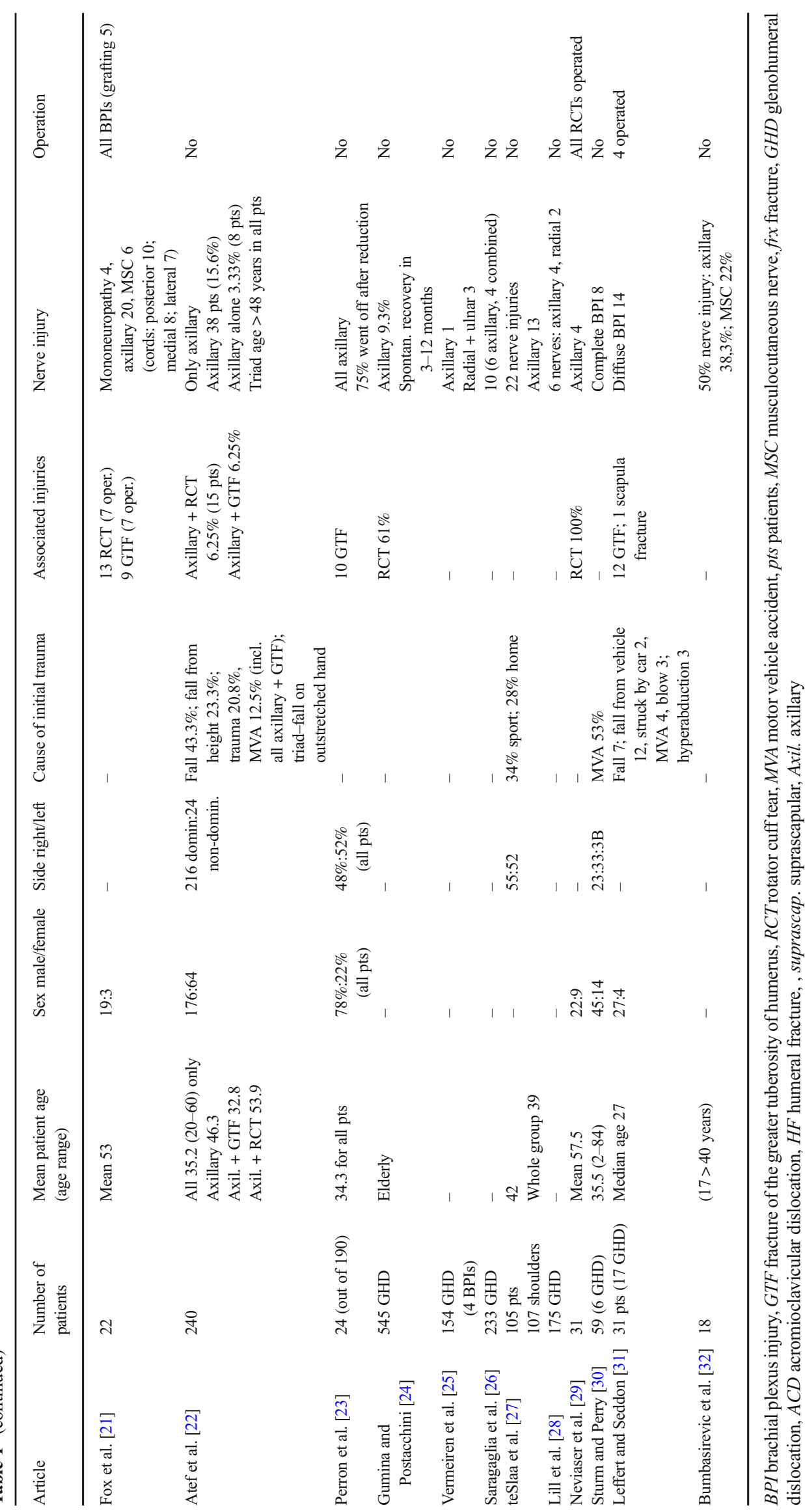


Table 2 Literature source file - case reports

\begin{tabular}{|c|c|c|c|c|c|c|c|}
\hline Article & Sex & Side & Cause of injury & Associated injuries & Nerve injury & Age & Operative treatment \\
\hline Dhar [33] & $\mathrm{F}$ & $\mathrm{R}$ & MVA & - & Diffuse & 32 & No \\
\hline Jerosch et al. [34] & M & - & - & - & MSC & 47 & - \\
\hline Saab $[35]$ & $\mathrm{F}$ & $\mathrm{R}$ & Fall from a horse & - & Diffuse & 49 & No \\
\hline Koulali-Idrissi et al. [36] & M & $\mathrm{R}$ & Fall & GTF & Total BPI & 52 & No \\
\hline Volpin et al. [37] & $\mathrm{F}$ & $\mathrm{R}$ & Fall from stairs & - & Total & 62 & Recovery in 9 months \\
\hline Volpin et al. [37] & $\mathrm{F}$ & $\mathrm{R}$ & Fall from stairs & - & $\begin{array}{l}\text { Total (ulnar nerve slowest } \\
\text { to recover) }\end{array}$ & 52 & Recovery in 12 months \\
\hline Ameh and Crane [38] & $\mathrm{F}$ & $\mathrm{R}$ & Fall & no & Radial + ulnar & 57 & No \\
\hline Chillemi et al. [39] & M & $\mathrm{L}$ & MVA & GTF & Posterior cord & 27 & No \\
\hline Sinha et al. [40] & M & $\mathrm{R}$ & Fall & - & Posterior + medial cord & 71 & No \\
\hline Shears et al. [41] & M & $\mathrm{L}$ & Fall & GTF & Posterior + medial cord & 32 & No \\
\hline Rathore et al. [42] & $\mathrm{F}$ & $\mathrm{R}$ & Fall from stairs & $\begin{array}{l}\text { Proximal humerus } \\
\text { fracture (oper.) }\end{array}$ & Median + radial & 53 & Good recovery in 3 months \\
\hline
\end{tabular}

Prolonged ischaemia leads to infarction of nerve which is equal to neurotmesis [54].

In some cases, the injury to neurovascular structures may be caused by abrupt or brutal reduction manoeuvre. Certain reduction techniques are more likely to cause such complications, including Hippocrates method, in which violent traction applied to outstretched arm combined with compression in the axillary region by the operator's heel may result in injury to neurovascular structures [4, 42, 59]. It is, therefore, essential to assess and document the neurological status of the limb, both before and after reduction attempt [51].

\section{Affection of particular nerves}

Out of all BPIs, those affecting its infraclavicular part constitute only $25 \%[60,64]$. However, injuries resulting from shoulder dislocation affect predominantly the infraclavicular part of the plexus at the level of cords and nerves, often extending up to retropectoralis minor space $[11,65,66]$. It may be explained by the fact that trauma in abduction causes primarily injury to the lower part of the brachial plexus [64]. Position of the limb during dislocation has been reported to influence the site of nerve injury. Major traction forces act upon the medial cord when the elbow and wrist are extended, the medial and posterior cords when the elbow is flexed and all cords when the arm is in $90^{\circ}$ abduction and full extension $[35,41,60]$. In the position of extreme abduction and internal rotation of the arm, which is observed during motorcycle accidents and causes opening of the scapulohumeral angle with wedging of the infraclavicular brachial plexus, injury to the nerves located closest to the shoulder joint, especially axillary, musculocutaneous and radial nerves, is most often found [7]. Pulling down by the limb in internal rotation causes injury to the motor branch of the axillary nerve, which winds around surgical neck of the humerus and leaves the more distally located sensory branch intact [7].

Shoulder dislocation most commonly causes injury to the axillary nerve, both when single nerve injury is considered and in combination with other nerves $[5,11,16,18,42]$. Axillary nerve was found to be affected in all patients with neurologic deficit after shoulder dislocation (100\%) in several studies [6, 7, 22, 23, 51, 67-70], and in all analysed studies but two (Hems and Mahmood, Stenning et al.), it occupied the first place among injuries to the long nerves of the brachial plexus [18, 54].

BPI manifested as mononeuropathy in $18.2 \%$ (Fox et al.) to $90.5 \%$ (Robinson et al.) of the cases [5, 7, 8, 10-12, 15-17, $19,21,22]$. In general, multiple nerve injuries were found more often than injury to a single nerve $[7,8,12,16,19,21$, 22]. In the study by Robinson et al., injury to the axillary nerve alone was more common in young individuals and as a result of high-energy trauma, while complex neurological deficits were associated with older age, female sex and low-energy fall [5]. Another study confirmed that single nerve injury is more likely to be a result of high-energy trauma in a younger patient, while multiple nerve injury would be a result of lowenergy fall in an elderly patient [19]. In the previously cited study by Robinson et al., percentage of multiple nerve lesions was significantly higher in the group with other associated injuries (rotator cuff tear (RCT)/GTF) [5].

The incidence of injuries to other nerves of the brachial plexus varied in different studies. In two studies comprising the largest numbers of patients, particular nerves were affected in the descending order of frequency: axillary, ulnar, median, radial and musculocutaneous nerve $[5,19]$. By contrast, in two other studies on relatively large patient groups, musculocutaneous nerve occupied the second position $[15,21]$.

In the studies analysing BPI after shoulder dislocation with reference to injury to particular cords, posterior cord was the most common to be injured $[16,21,60]$. 
Total brachial plexus palsy (affection of all five long nerves of the brachial plexus) was observed in $2.7 \%$ [15] to $41.7 \%$ [17] of all nerve injuries, and in the studies by Robinson et al. and Gutkowska et al., it was associated with the presence of GTF $[5,18,19,30]$.

Shoulder dislocation can cause injury not only to the long nerves but also the short branches of the brachial plexus. Out of the short nerves of the brachial plexus, suprascapular nerve injury has been reported in the largest number of studies [7-9, $17,71,72]$. Its distance from the posterior glenoid rim has been reported to be averagely $1.8 \mathrm{~cm}$ and its relative fixity at the scapular notch makes this nerve susceptible to traction injury [56, 72-75]. The symptoms of suprascapular nerve injury are often vague and unspecific, manifesting as pain and muscle weakness [74]. The clinical images of axillary and suprascapular nerve injuries overlap and are difficult to differentiate without nerve conduction studies. Injury to these two nerves can also coexist, which leads to severe impairment of arm movement $[7,17,71]$. The clinical picture may also resemble RCT and even shoulder instability [74]. Clinical examination and electromyography (EMG) of the supraspinatus and infraspinatus muscles should be performed. The treatment is nonoperative in the majority of the cases but spontaneous recovery may take more than 1 year $[72,74]$. However, in some cases, this injury may require operative treatment (neurolysis) in order to relieve pain, improve spinati muscles function and prevent their atrophy [71, 74]. Kline et al. observed that in cases of combined axillary and suprascapular nerve injury, suprascapular nerve function improved spontaneously in the majority of the cases, while axillary nerve more often required operative intervention [71].

\section{Severity of lesions}

Nerve injury complicating shoulder dislocation most often is neurapraxia or axonotmesis according to Seddon or first to fourth degree injury according to Sunderland $[33,42,54$, $56,67,75,76]$. Complete disruption of nerve continuity or its avulsion is very rare due to the fact that traction is exerted at a point relatively distant to the point of exit of nerve roots from the spinal cord and the plexus is mobile and extensible at this level, as well as thanks to the relatively low energy of injury being in most cases simple fall $[6,33,35]$.

In the analysed literature, complete nerve disruption was rare and observed only for the axillary nerve. It occurred in $2.4 \%$ of the patients in the study by Hems and Mahmood and in $2.7 \%$ of the patients analysed by Gutkowska et al. (in all cases as a result of high-energy trauma) $[18,19]$. In cases of terrible triad, neurotmesis requiring repair with nerve grafting was more frequent and occurred in $22.7 \%$ of the patients in the study by Fox et al. and in $29 \%$ of the patients studied by Rovesta et al. [21, 51].

\section{Risk factors for neurological complications}

Elevated risk of neurological injury after shoulder dislocation is associated with a number of variables. The most important of them is higher patient age $[5,10,12,14,77]$. Several studies confirmed that mean age of the patients who sustained isolated shoulder dislocation was lower than those who suffered neurological complications [18, 22, 23, 27, 28]. Visser et al. found the probability of neural injury to increase with a factor of 1.3 per every 10-year period [15]. Due to predominance of men in the studied patient groups, male sex can also be considered a risk factor. However, in the comprehensive study by Robinson et al., demographic features of the group of patients with neurological deficit alone did not differ from the general population of dislocators [5].

Conflicting opinions can be found in the literature regarding the influence of the energy of the initial trauma causing dislocation on the risk of BPI. High-energy trauma has been postulated to be connected with an elevated risk by Pasila et al. and Yeap et al., while Robinson et al. found more neurological complications in patients who suffered low-energy injury $[5,12,13]$.

Longer time period between dislocation and its reduction has been associated with higher risk of neural complications $[12,14,19]$. More neural complications have also been observed after first time than after recurrent shoulder dislocations [14, 49].

As far as associated injuries are concerned, according to Robinson et al., the likelihood of neurological deficit is significantly higher for patients with coexisting RCT or GTF (RR 1.9) [5]. In the study by Visser et al., the presence of GTF doubled the incidence of nerve injury [15].

Higher incidence of nerve injuries was also connected with the presence of coexisting haematoma, with the adverse effect noticeable both in terms of severity of injury and the number of nerves involved [11,15].

\section{Accompanying injuries}

In the study by Robinson et al., in 5.8\% of the patients, neurological deficit was the only complication of shoulder dislocation, while in $7.8 \%$, it was found together with RCT (2.1\%) or GTF (5.7\%) [5]. In another study on 240 patients, only $3.3 \%$ of them suffered isolated neurological deficit, while in $6.25 \%$ of the cases, it was associated with RCT or GTF [22]. Hems and Mahmood found GTF/RCT in 31\% of their patients treated for injury to the infraclavicular part of the brachial plexus [18]. Patients diagnosed with neurological deficit and RCT were characterised by higher mean age in comparison to the whole patient group, while coincidence of GTF and nerve injury was generally found in younger patients (Table 3 ). 
Table 3 Mean age of the patients with and without accompanying injuries

\begin{tabular}{llll}
\hline Article & Whole patient group & BPI+GTF & BPI+RCT \\
\hline Robinson et al. [5] & 51.5 years & 56.3 years & 63.0 years \\
Gutkowska et al. [78] & 50 years and 1 month & 48 years and 8 months & 54 years and 8 months \\
Atef et al. [22] & 35.2 years & 32.8 years & 53.9 years \\
\hline
\end{tabular}

\section{Rotator cuff tear/fracture of the greater tuberosity of humerus}

Association of BPI and RCT after shoulder dislocation was first described by Gonzales and Lopez in 1991 [79] and is known under the term "unhappy triad" [80] or "terrible triad" [81] of the shoulder [79-80]. This complex injury is found more often in patients over 50 years of age and usually coexists with injury to the axillary nerve alone $[9,10,15,29,66$, $70,82]$. The incidence of terrible triad varied between 2 and $18 \%$ in the analysed literature $[5,10,11,13-15,17,19,20$, 22] (Table 4). Inability to initiate abduction and weakening of external rotation of the arm should raise the suspicion of a complicated dislocation [29, 70, 79, 81, 83]. Differentiation between RCT and nerve injury as causes of shoulder disability after dislocation can be difficult based on clinical examination alone [67]. According to some authors, axillary nerve injury does not cause complete absence of shoulder abduction so this symptom indicates the presence of RCT $[18,51]$. Out of the two, RCT is a more common cause of upper limb weakening and pain in older patients due to degeneration of collagen fibres composing tendons, which progresses with age $[5,51$, 70]. Displaced GTF is a functional equivalent of rotator cuff discontinuity $[51,79]$. Association of GTF and nerve injury was found in $5.7-32 \%$ of the patients in the analysed literature $[5-7,11,15,19,22]$. Robinson et al. suggest that "in the absence of GTF on postreduction radiograph, it is advisable to image the rotator cuff in patients with more complex neurological deficit" [5]. To differentiate between RCT and nerve injury, magnetic resonance imaging (MRI), computed tomography (CT) arthrography or ultrasound should be performed as soon as possible to confirm RCT and avoid unnecessary intervention on the brachial plexus [67, 83]. However, even when RCT has been diagnosed, EMG testing for nerve injury should be conducted, as the two injuries often mask each other $[70,79,80]$. RCT requires early operative repair, especially in younger patients in order to improve functional recovery and avoid muscle atrophy, while the approach to nerve injury should be conservative in the initial phase $[5,10,12,17,18,20,21,41,51,66,70$, $79-80,83,84,86,87]$. However, if adequate RCT reconstruction does not cause the limb movement to improve, nerve function should be reassessed and operative treatment considered $[17,18]$. According to Strafun et al., if in preoperative EMG examination more than $30 \%$ of axillary nerve conduction is preserved, the patient should be operated-on for RCT and the treatment of neural injury should be conservative, but if conduction is less than $30 \%$, early surgical exploration of axillary nerve is advocated [20]. Simonich et al. concluded that the final functional result of the affected limb is more dependent on nerve recovery than on complete RCT repair [70].

\section{Neurovascular injury}

A rare but devastating sequelae of shoulder dislocation is complex neurovascular injury with trauma to both brachial plexus and axillary or rarer subclavian artery [37, 59, 61]. Vascular injury is observed in up to $25 \%$ of infraclavicular lesions [60]. In the analysed literature, 29 cases of neurovascular injury complicating shoulder dislocation have been identified, out of which $75 \%$ occurred in patients older than 60 years (Table 5). This injury is more common in elderly patients, whose arteries are atherosclerotic, less elastic and therefore more susceptible to tear as a result of forced traction during dislocation or reduction manoeuvres $[18,61-63$, 88-91]. Axillary artery is injured in its third portion (between the inferior borders of pectoralis minor and teres minor muscles) in $90 \%$ of the cases [88]. In the position of abduction and external rotation of the arm, the artery becomes tense [89]. The mechanism of injury is complex: the artery is suddenly pulled and stretched over the edge of pectoralis minor muscle which acts as a fulcrum, in case of recurrent dislocation or arthritic changes of the shoulder joint it can be torn by adhesions existing between its walls and the surrounding tissues, and the dislocated humeral head exerts pressure on the artery $[18,61,88]$. At the level of the axilla, brachial plexus and axillary artery are invested by a common connective tissue sheath [54]. Thus, even minimal swelling within the sheath can cause compression on plexus elements [54]. Expanding haematoma or rarer pseudoaneurysm contributes to deterioration of neural function of the limb $[11,15,18,31,38,59,62$, $63,89]$. Moreover, occlusion of axillary artery may result in nerve ischaemia $[54,59]$. The onset of nerve palsy in such cases is delayed and the symptoms worsen in time [59, 62, 63]. Therefore, evidence of plexopathy or isolated neuropathy after shoulder dislocation should always raise a suspicion of coexisting arterial injury $[62,68,93]$. Similarly, the presence of vascular injury may provide information about the site and severity of nerve lesions [86]. According to Stenning et al., particularly close relationship between median nerve trunk and the axillary artery causes this nerve to be most commonly 


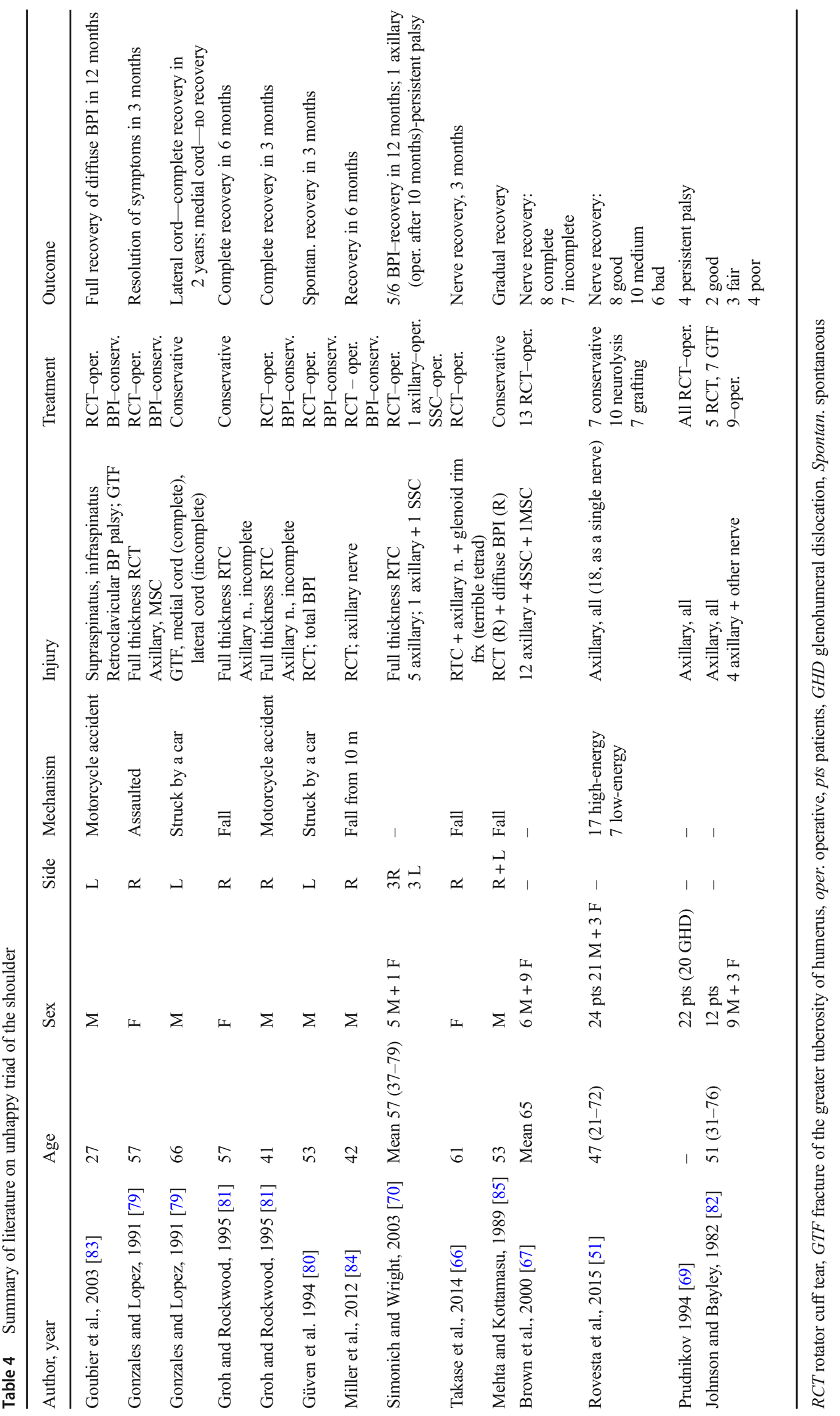




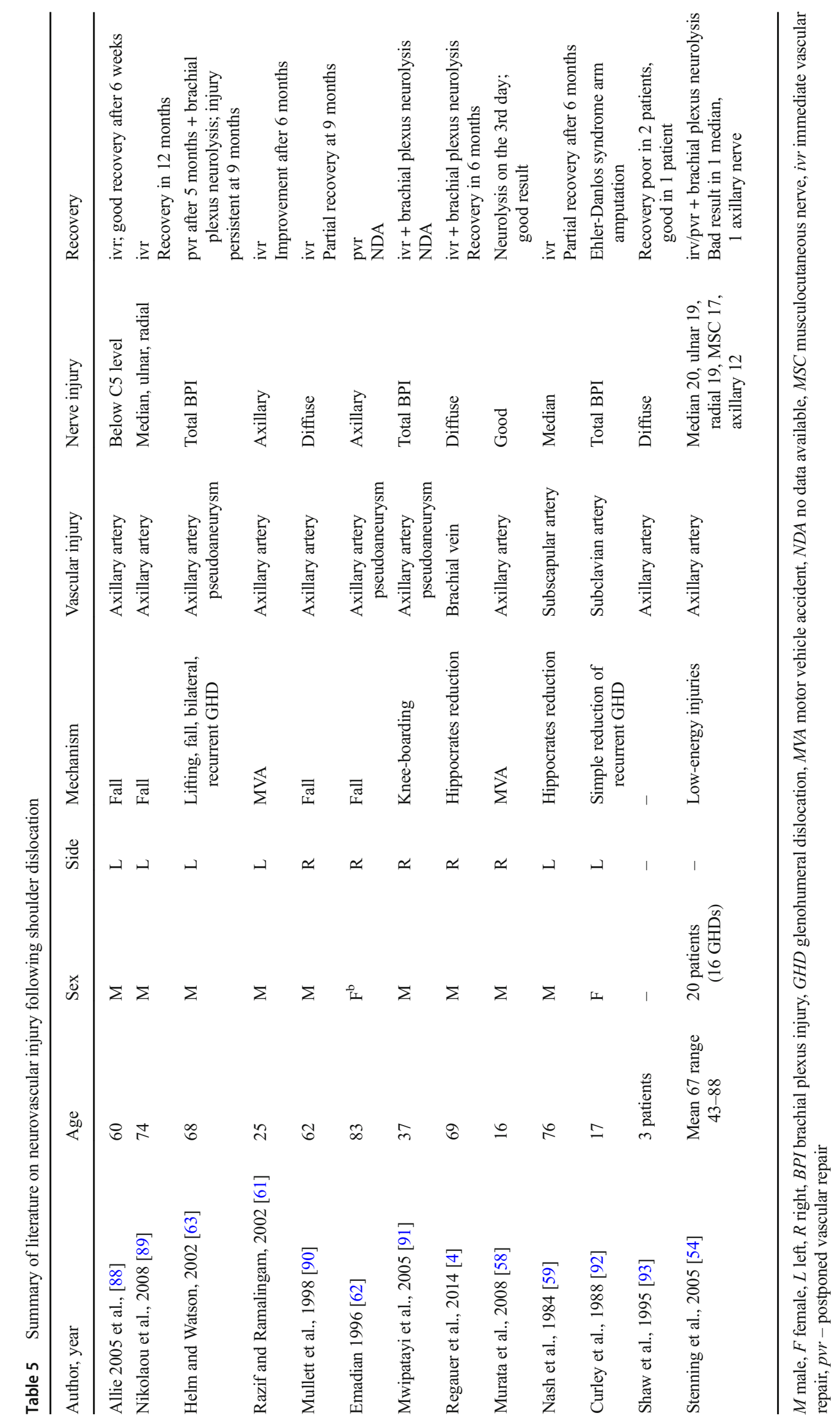


involved in periarterial fibrosis or incorporated into the wall of pseudoaneurysm [54]. In the analysed literature, arterial injury in the majority of the cases coexisted with diffuse or complete injury to the brachial plexus. Due to rich collateral circulation, the presence of palpable distal pulses does not preclude axillary artery injury [18, 59-62, 88, 91]. In case of suspected arterial injury, CT angiography or arteriography is required to confirm the diagnosis, followed by immediate surgical intervention to reconstruct the arterial defect and evacuate haematoma. Brachial plexus should be simultaneously explored, subjected to decompression and external neurolysis to relieve pressure on nerves, avoid irreversible neurological damage and promote spontaneous recovery $[18,54,58,59]$. According to Shaw et al., the long-term outcomes in neurovascular injury depend more on nerve regeneration than arterial injury, which can be easily repaired operatively [93].

\section{Percentage of patients requiring operation}

Infraclavicular lesions require operative treatment significantly less often than injuries to supraclavicular brachial plexus and in the majority of the cases spontaneous improvement or return of limb function can be expected after a period of observation and/ or rehabilitation $[11,15,53,60,64,66]$. Spontaneous recovery of injured nerves has been described in $75-100 \%$ of the patients in some studies $[15,23,24,26]$. Still, regenerative capacity decreases with age, which leads to complete lack or only limited recovery, with residual reduction of limb mobility observed in up to $60 \%$ of the patients $[14,38,82]$.

In two large studies on 819 and 1019 patients, only 17 and $14 \%$, respectively required operative treatment for stretch/ contusion to infraclavicular part of the brachial plexus [94, 95]. In another study on multitrauma victims, $17 \%$ of the patients with infraclavicular lesions as opposed to $52 \%$ with supraclavicular lesions required operative intervention [53]. Similar numbers (13-18\% of patients requiring surgery for BPI after shoulder dislocation) have been reported by other authors $[6,18,31]$.

\section{Time frame for operation}

Cease of neural impulsation to an effector muscle causes denervation which in the early stage is manifested by oedema and in time leads to fatty degeneration of the muscle [96]. After 23 months, decrease by $50 \%$ in the fibre diameter can be observed and after another 1-2 months massive accumulation of interstitial collagen begins $[64,97]$. Intramuscular fibrosis impairs muscle mechanical function and prevents intramuscular axonal regeneration, which in turn affects neuromuscular synaptogenesis via changes in expression of myogenic regulatory factors, neurotrophic factor receptors, nicotinic acetylcholine receptor and nerve cell adhesion molecule, causing reduction in the number of motor end plates [97]. Such changes can be observed as early as after 3 months from the injury [98]. After 2 years, muscle fibre disintegration can be seen and between 1 and 3 years muscle fibres are replaced with adipose and fibrous connective tissue [64].

Timing of brachial plexus surgery after shoulder dislocation remains a controversial issue, which needs balancing between allowing time for spontaneous nerve regeneration and undertaking operative intervention before denervation atrophy occurs that would render the muscles refractory to reinnervation [99]. It is generally accepted that more than 12-18 months' interval between denervation and reinnervation causes the return of muscle function unlikely to be successful [97]. More satisfactory sensory recovery can also be expected when the time interval between injury and surgery is shorter [100].

Optimal time frame for operative intervention in closed BPIs is considered between 6 and 9 months, according to current literature [101]. It allows time for the regenerating axon to reach its target muscle before irreversible degeneration of motor end plate [87, 97, 101-103]. Most authors believe that operative intervention should be postponed until 36 months after the injury, because it is impossible to differentiate between neurotmesis and neurapraxia before the latter wears off $[6,7,27,39,42,51,60,102,104,105]$. According to Battiston et al., the optimal interval between the injury and surgery is 5.4 months [60].

However, early surgery within 3 months from the injury is being advocated by a growing number of authors. Early operative treatment has been postulated to prevent formation of perineural scar compressing healthy nerve fascicles and further worsening of symptoms [21, 60, 65, 106]. Patients with confirmed nerve discontinuity are best candidates for early operative reconstruction, which can be especially beneficial in this patient group, in which there is no chance to obtain improvement without surgical intervention. In cases of preserved nerve continuity and lack of any regenerative signs, both clinically and in EMG examination, nerve reconstruction can also be performed early, within 3 months from the initial trauma. The advantages of early surgical intervention include early reinnervation before end plate degeneration and irreversible changes in the effector muscles, alleviation of pain associated with neural injury and prevention of neuroma formation with regrowth of axons into the scar tissue $[21,60,65,106]$.

New or improved, safe and non-invasive imaging modalities have recently gained importance in diagnosis, decision-making and treatment of peripheral nerve injuries. These include magnetic resonance neurography (MRN) and high-resolution nerve sonography (frequency $=7$ $12 \mathrm{MHz}$ or more) [107, 108]. They enhance diagnostic accuracy and help in determination of surgical feasibility and planning. The fact that these imaging techniques can 
provide useful information immediately after the injury, as opposed to EMG, which requires a delay before it becomes diagnostic, is an important advantage [107]. As a result, in some cases, early effective treatment can be implemented instead of following the wait-and-see strategy. When performed and interpreted by an experienced examiner, these techniques are able to adequately depict nerve disruption manifested by abrupt termination of the nerve and oedema of the surrounding tissues, massive haematomas or large neuromas, along with precise identification of the level of injury [107-111]. Large haematomas revealed in the infraclavicular region should be evacuated and brachial plexus inspected concurrently before resulting fibrosis causes compression of neural elements. Similarly, in a rare event when shoulder dislocation results in axillary nerve disruption, the nerve would benefit from an early reconstructive procedure. It is difficult to distinguish between nerve disruption and closed nerve injury that has chances for recovery on the basis of clinical examination and EMG alone [107]. In such cases, MRN helps to determine whether surgery would be beneficial [107].

\section{Preferred operative method}

The type of surgical procedure depends on severity of injury to neural structures, time elapsed from the trauma to operation and response to electrophysiological and nerve action potentials testing. Careful pre- and intraoperative assessment of the severity and type of nerve lesion is extremely important, because unnecessary resection of a regenerating brachial plexus element or performing solely neurolysis of elements for which there is no chance for regeneration does the patient a great harm [99]. External neurolysis is sufficient in cases with nerve continuity and present regenerative nerve action potentials (NAPs) $[60,78,112]$. In such cases, the reason for impairment or loss of limb function is external scarring (fibrosis) causing compression on the elements of the brachial plexus. Microsurgical decompression performed early after trauma with the use of operating microscope or loupe magnification can lead to improvement in nerve conductivity resulting in improved limb function. Neurolysis needs to be performed in a subtle manner in order to avoid fascicular devascularisation [113]. Additional internal neurolysis is required when severe neuropathic pain accompanies or when thickened epineurium compressing nerve bundles and causing compromise of vasa nervorum is observed intraoperatively $[60,78,112,114,115]$. When disruption of nerve continuity is observed or regenerative NAPs are absent in a continuous nerve, grafting (usually with the use of sural nerve) should be implemented. However, according to some authors, nerve resection and grafting are not recommended during primary operative intervention, because in certain injury patterns improvement in nerve function after operation is possible only after axon regeneration (enabled by restoration of blood flow to the nerve by means of neurolysis) has been completed [77, 78, 94]. During operative exploration of the injured brachial plexus, anatomic relations of particular structures are usually altered due to the presence of a fibrous scar [94]. Coexisting injuries or status after previous surgical interventions in the axillary region (RCT repair, humeral fracture stabilisation, arterial repair) make the operation even more demanding and challenging.

After operative treatment, the patient should be followedup for at least 2 years and preferably 5 years [87]. If more than 18 months passed between the injury and surgery, nerve repair has little chance to result in any improvement and tendon transfers, muscle transposition or arthrodesis should be considered to restore basic function of the affected limb [87, 102].

\section{Recovery}

Infraclavicular lesions are generally considered to be milder and associated with better prognosis for recovery [94]. However, Kim et al. in their retrospective study covering more than 1000 patients with BPIs treated over a 30-year-long period found that functional loss in infraclavicular lesions was equally severe and resistant to resolve in time [95]. Moreover, they also concluded that stretch injuries have worse prognosis than sharp ones because the affected part of the nerve is longer $[21,95]$. Similarly, Terzis et al. having analysed 204 cases of BPI did not confirm tendency towards more favourable outcomes in infraclavicluar lesions [116].

In the course of conservative treatment, first detectable signs of reinnervation can be seen after 1-2 months or, according to other authors, after 3-4 months and it is when initial improvement in nerve function can be expected [60, 64, 117]. These observations confirm the validity of performing serial EMGs to prognosticate and make recommendations for treatment (waitand-see strategy versus operative intervention). Sensory recovery precedes motor recovery and constitutes a good indicator $[6,33]$. Deep pressure sensation has been suggested to be the best indicator of recovery potential [6]. Evidence of early recovery may be detectable in EMG weeks to months before clinically apparent limb function improvement [87].

First signs of postoperative recovery can be expected 2 months after neurolysis or 3 months after grafting, and the regeneration process is usually complete by the $6-18$ th month after operation $[6,7]$. The worst results regarding motor recovery have been observed for the intrinsic muscles of the hand $[6,9,18]$. This is caused by a long distance that needs to be covered by regenerating axons and the tendency towards quick atrophy of these muscles $[9,18]$. Improvement in function of intrinsic muscles of the hand can be expected after a significantly longer period of time, up to 36 months [31]. 


\section{Factors influencing recovery}

A number of factors influencing nerve recovery have been identified.

Wehbe et al., having analysed the results of operative treatment of 33 cases of axillary nerve injury, determined that recovery was better in patients below 25 years of age, while
Battistion et al. connected higher chances for spontaneous recovery with patient age below 40 years $[7,60]$. Relationship between recovery potential and patient age has also been confirmed by Visser et al. [15].

Increasing severity of nerve lesions, requiring more invasive operative treatment, correlates with poorer functional outcome $[21,60]$. The best recovery of muscle strength has been

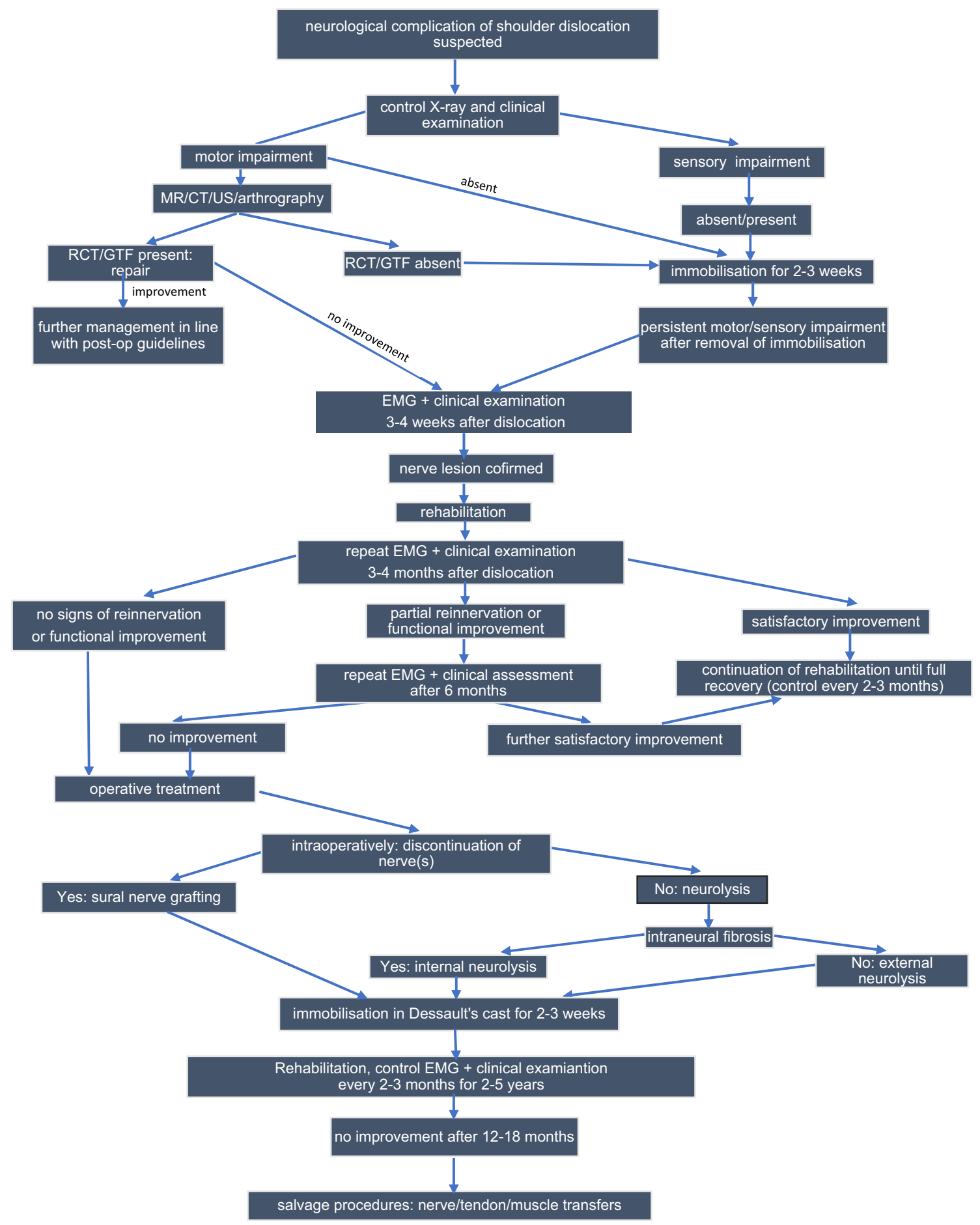

Fig. 1 Management algorithm in patients with suspected neurological injury after shoulder dislocation 
observed in patients who did not require operative intervention, the results were slightly worse in patients who required neurolysis and even worse in those, who had to have nerve grafting performed [51]. Superior results obtained after neurolysis in comparison to grafting have been confirmed by other authors [7, 95]. In case of grafting, according to Wehbe et al., recovery was better when the graft length was below $6 \mathrm{~cm}$ [7]. The relationship between the graft length and the outcome has not been confirmed by other authors $[6,102,114]$.

Another important factor influencing the recovery was time period elapsed between the initial trauma and surgery. All authors analysing this factor agreed that the outcomes were better when the operation was performed early, preferably within 6 months [7, 19, 21, 86, 114, 116].

Conflicting evidence has been found regarding the influence of injury to a single or multiple nerves on recovery. While Wehbe et al. observed better recovery in lesions of an isolated nerve, other authors found isolated lesion of axillary nerve to be associated with worst prognosis $[6,7,19]$.

The results depended also on the most affected cord - they were best for lateral cord, medium for posterior cord and least favourable for medial cord, especially the ulnar nerve [95]. Inferior results and longer time required for recovery of the median and ulnar nerves have been observed by many authors $[9,18,31,37,77,78]$.

Some authors noticed that recovery was better when no associated lesions were present $[7,60]$.

\section{Summary}

Loss of shoulder motion after dislocation, especially in older patients, is often attributed to immobilisation and stiffness, which may mask neurological injury [42]. All patients manifesting muscle weakness or altered sensation after shoulder dislocation require systematic control. The first EMG examination should be performed with a delay of at least 3 weeks because only then fibrillation potentials as a sign of denervation become evident $[15,18,60,64,66,84,102,117]$. Nonoperative treatment is a commonly recommended approach in infraclavicular BPIs resulting from shoulder dislocation $[6,11,18,31,66]$. However, operative intervention should be considered when conservative approach does not bring improvement in a maximum period of 6 months. According to a growing number of authors, early surgery within 3 months from the initial trauma is especially beneficial. Recommended management algorithm in neurological complications of shoulder dislocation has been presented in Fig. 1.

Physiotherapy plays an extremely important role in the management of BPI. It prevents range of motion limitations, muscular contractures, joint stiffness, muscle atrophy, development of secondary deformities and helps supress pain. Its major goal is to maintain adequate muscle trophism during reinnervation $[64,87]$.

Treatment of BPI requires long-lasting cooperation between the patient, surgeon, physiotherapist and often also psychological support in order to obtain useful recovery of limb function [84]. In a satisfaction survey conducted among patients who underwent surgery to treat traumatic injury to the brachial plexus, $87 \%$ of the patients were satisfied with the outcome of operation and $83 \%$ claimed they would undergo the operation again [118].

\section{Compliance with ethical standards}

Conflict of interest The authors declare that they have no conflict of interest.

Ethical approval For this type of study, formal consent is not required.

This article does not contain any studies with human participants or animals performed by any of the authors.

The approval granted by the Local Bioethics Committee of Wroclaw Medical University for a broader scientific project entitled "Brachial plexus injuries without disruption of continuity of neural elements in adults (subtitle: Neurological complications after glenohumeral dislocation and proximal humeral fractures)" is available from the authors on request.

Informed consent This article, being a literature review, does not contain any studies with human participants performed by any of the authors, and is based solely on the analysis of previously published literature.

Open Access This article is distributed under the terms of the Creative Commons Attribution 4.0 International License (http:// creativecommons.org/licenses/by/4.0/), which permits unrestricted use, distribution, and reproduction in any medium, provided you give appropriate credit to the original author(s) and the source, provide a link to the Creative Commons license, and indicate if changes were made.

\section{References}

1. Gleeson A (1998) Anterior glenohumeral dislocations: what to do and how to do it. J Accid Emerg Med 15:7-12

2. Hovelius L, Olofsson A, Sandström B, Augustini BG, Krantz L, Fredin $\mathrm{H}$ et al (2008) Nonoperative treatment of primary anterior shoulder dislocation in patients forty years of age and younger: a prospective twenty-five-year follow-up. J Bone Joint Surg Am 90: 945-952. https://doi.org/10.2106/JBJS.G.00070

3. Milton GW (1953) The mechanism of circumflex and other nerve injuries in dislocation of the shoulder, and the possible mechanism of nerve injuries during reduction of dislocation. ANZ J Surg 23: 25-30. https://doi.org/10.1111/j.1445-2197.1953.tb05013.x

4. Regauer M, Polzer H, Mutschler W (2014) Neurovascular complications due to the Hippocrates method for reducing anterior shoulder dislocations. World J Orthop 5:57-61. https://doi.org/ 10.5312/wjo.v5.i1.57

5. Robinson CM, Shur N, Sharpe T, Ray A, Murray IR (2012) Injuries associated with traumatic anterior glenohumeral dislocations. J Bone Joint Surg Am 94:18-26. https://doi.org/10.2106/ JBJS.J.01795 
6. Travlos J, Goldberg I, Boome RS (1990) Brachial plexus lesions associated with dislocated shoulders. J Bone Joint Surg (Br) 72: 68-71

7. Wehbe J, Maalouf G, Habanbo J, Chidiac RM, Braun E, Merle M (2004) Surgical treatment of traumatic lesions of the axillary nerve. A retrospective study of 33 cases. Acta Orthop Belg 70: $11-18$

8. Liveson JA (1984) Nerve lesions associated with shoulder dislocation; an electrodiagnostic study of 11 cases. J Neurol Neurosurg Psychiatry 47:742-744

9. Kosiyatrakul A, Jitprapaikulsarn S, Durand S, Oberlin C (2009) Recovery of brachial plexus injury after shoulder dislocation. Injury 40:1327-1329. https://doi.org/10.1016/j.injury.2009.05. 015

10. Toolanen G, Hildingsson C, Hedlund T, Knibestöl M, Oberg L (1993) Early complications after anterior dislocation of the shoulder in patients over 40 years. An ultrasonographic and electromyographic study. Acta Orthop Scand 64:549-552

11. de Laat EA, Visser CP, Coene LN, Pahlplatz PV, Tavy DL (1994) Nerve lesions in primary shoulder dislocations and humeral neck fractures. A prospective clinical and EMG study. J Bone Joint Surg (Br) 76:381-383

12. Yeap JS, Lee DJ, Fazir M, Kareem BA, Yeap JK (2004) Nerve injuries in anterior shoulder dislocations. Med J Malaysia 59:450 454

13. Pasila M, Jaroma H, Kiviluoto O, Sundholm A (1978) Early complications of primary shoulder dislocations. Acta Orthop Scand 49:260-263

14. Pasila M, Kiviluoto O, Jaroma H, Sundholm A (1980) Recovery from primary shoulder dislocation and its complications. Acta Orthop Scand 51:251-257

15. Visser CP, Coene LN, Brand R, Tavy DL (1999) The incidence of nerve injury in anterior dislocation of the shoulder and its influence on functional recovery. A prospective clinical and EMG study. J Bone Joint Surg (Br) 81:679-685

16. Visser CP, Tavy DL, Coene LN, Brand R (1999) Electromyographic findings in shoulder dislocations and fractures of the proximal humerus: comparison with clinical neurological examination. Clin Neurol Neurosurg 101:86-91

17. Payne MW, Doherty TJ, Sequeira KA, Miller TA (2002) Peripheral nerve injury associated with shoulder trauma: a retrospective study and review of the literature. J Clin Neuromuscul Dis $4: 1-6$

18. Hems T, Mahmood F (2012) Injuries of the terminal branches of the infraclavicular brachial plexus. Patterns of injury, management and outcome. J Bone J Surg Br 94:799-804. https://doi.org/10. 1302/0301-620X.94B6.28286

19. Gutkowska O, Martynkiewicz J, Stępniewski M, Gosk J (2018) Analysis of patient-dependent and trauma-dependent risk factors for persistent brachial plexus injury after shoulder dislocation. Biomed Res Int 10:4512137. https://doi.org/10.1155/2018/ 4512137

20. Strafun SS, Bogdan SV, Lysak AS (2009) Treatment of a "terrible triad" of the shoulder. Trauma 17:46-52. https://doi.org/10.22141/ 1608-1706.6.17.2016.88617

21. Fox M, Lambert S, Birch R (2009) The terrible triad of the shoulder. Bone Joint J 91-B(Suppl 1):13-20

22. Atef A, El-Tantawy A, Gad H, Hefeda M (2016) Prevalence of associated injuries after anterior shoulder dislocation: a prospective study. Int Orthop 40:519-524

23. Perron AD, Ingerski MS, Brady WJ, Erling BF, Ullman EA (2003) Acute complications associated with shoulder dislocation at an academic emergency department. J Emerg Med 24:141-145

24. Gumina S, Postacchini F (1997) Anterior dislocation of the shoulder in elderly patients. J Bone Joint Surg (Br) 79:540-543
25. Vermeiren J, Handelberg E, Casteleyn PE, Opdecam E (1993) The rate of recurrence of traumatic anterior dislocation of the shoulder. A study of 154 cases and a review of the literature. Int Orthop 17: 337-341

26. Saragaglia D, Picard F, Le Bredonchel T, Moncenis C, Sardo M, Tourne Y (2001) Acute anterior instability of the shoulder: shortand mid-term outcome after conservative treatment. Rev Chir Orthop Reparatrice Appar Mot 87:215-220

27. te Slaa RL, Wijffels MP, Brand R, Marti RK (2004) The prognosis following acute primary glenohumeral dislocation. J Bone Joint Surg (Br) 86:58-64

28. Lill H, Verheyden P, Korner J, Hepp P, Josten C (1998) Konservative Behandlung nach traumatischer Schultererstluxation. Chirurg 6:1230-1237

29. Neviaser RJ, Neviaser TJ, Neviaser JS (1988) Concurrent rupture of the rotator cuff and anterior dislocation of the shoulder in the older patient. J Bone Joint Surg Am 70:1308-1311

30. Sturm JT, Perry JF Jr (1987) Brachial plexus injuries from blunt trauma - a harbinger of vascular and thoracic injury. Ann Emerg Med 16:404-406

31. Leffert R, Seddon H (1965) Infraclavicular brachial plexus injuries. J Bone J Surg Br 47:9-22

32. Bumbasirević M, Lesić A, Vidaković A, Sudić V (1993) Nerve lesions after acute anterior dislocation of the humero-scapular joint — electrodiagnostic study. Med Pregl 46:191-193

33. Dhar D (2007) Anterior dislocation of shoulder with brachial plexus injury. J Coll Physicians Surg Pak 17:110-111

34. Jerosch J, Castro WH, Geske B (1990) Damage of the long thoracic and dorsal scapular nerve after traumatic shoulder dislocation: case report and review of the literature. Acta Orthop Belg 56:625-627

35. Saab M (2004) Brachial plexus lesion following an anterior dislocation of the shoulder. Eur J Emerg Med 11:168-169. https://doi. org/10.1097/01.mej.0000103473.32882.92

36. Koulali-Idrissi K, Sennoune B, Hachimi K, Messary O, Fnini S, Ouarab M et al (2003) Complete brachial plexus paralysis in anterior shoulder dislocation: a case report. Chir Main 22:109-111

37. Volpin G, Langer R, Stein H (1990) Complete infraclavicular brachial plexus palsy with occlusion of axillary vessels following anterior dislocation of the shoulder joint. J Orthop Trauma 4:121-123

38. Ameh V, Crane S (2006) Nerve injury following shoulder dislocation: the emergency physician's perspective. Eur J Emerg Med 13:233-235

39. Chillemi C, Marinelli M, Galizia P (2008) Fracture-dislocation of the shoulder and brachial plexus palsy: a terrible association. J Orthop Traumatol 9:217-220. https://doi.org/10.1007/s10195008-0028-0

40. Sinha A, Perry J, Weiss L (2007) Brachial plexus injury following anterior dislocation of the shoulder: a case report. Arch Phys Med Rehbil 88:E43

41. Shears E, Sunderamoorthy D, Ali SA (2005) Brachial plexus injury after anterior shoulder dislocation: a case report. Acta Orthop Belg 71:489-490

42. Rathore S, Kasha S, Yeggana S (2017) Fracture dislocation of shoulder with brachial plexus palsy: a case report and review of management options. J Orthop Case Rep 7:48-51. https://doi.org/ 10.13107/jocr.2250-0685.746

43. Delbit P, Cauchoix A (1910) Les paralysies dans les luxations de l'epaula. Rev Chir 41:327

44. Murray CR (1931) J Am Med Ass 104:337

45. DePalma AF (1951) Surgery of the Shoulder. JB Lippincott, Philadelphia pp 212

46. Watson-Jones R (1952) Fractures and joint injuries. E\&S Livingstone, Edinburgh

47. Blom S, Dahlbäck LO (1970) Nerve injuries in dislocations of the shoulder joint and fractures of the neck of the humerus. A clinical and electromyographical study. Acta Chir Scand 136:461-466 
48. Bohu Y, Klouche S, Lefevre N, Peyrin JC, Dusfour B, Hager JP, Ribaut A, Herman S (2015) The epidemiology of 1345 shoulder dislocations and subluxations in French Rugby Union players: a five-season prospective study from 2008 to 2013 . Br J Sports Med 49:1535-1540. https://doi.org/10.1136/bjsports-2014-093718

49. McLaughlin HL, MacLellan DI (1967) Recurrent anterior dislocation of the shoulder. II. A comparative study. J Trauma 7:191201

50. Mumenthaler M, Schliak H (1991) Peripheral nerve lesions: diagnosis and therapy. Georg Thyme Verlag, Stuttgart

51. Rovesta C, Marongiu C, Celli L (2015) Glenohumeral joint dislocation associated with nerve injuries and cuff tear (terrible triad). In: Peretti G (ed) Neurologic shoulder, 1st edn. TIMEO Editore, Bologna, pp 139-149

52. Rowe CR, Sakellarides HT (1961) Factors related to recurrences of anterior dislocations of the shoulder. Clin Orthop 20:40-48

53. Midha R (1997) Epidemiology of brachial plexus injuries in a multitrauma population. Neurosurgery 40:1182-1188

54. Stenning M, Drew S, Birch R (2005) Low-energy arterial injury at the shoulder with progressive or delayed nerve palsy. J Bone Joint Surg (Br) 87:1102-1106

55. McGregor AL (1942) A synopsis of surgical anatomy. John Wright and Sons, Bristol

56. Seddon H (1943) Three types of nerve injury. Brain 66:238-283

57. Stevens JH (1934) Brachial plexus paralysis. In: Codman EA (ed) The shoulder: rupture of the supraspinatus tendon and other lesions in or about the subacromial bursa, reprint. Kreiger, Melbourne

58. Murata K, Maeda M, Yoshida A, Yajima H, Okuchi K (2008) Axillary artery injury combined with delayed brachial plexus palsy due to compressive hematoma in a young patient: a case report. J Brachial Plex Peripher Nerve Inj 3:9. https://doi.org/10.1186/ 1749-7221-3-9.

59. Nash E, Soudry M, Abrahamson J, Mendes DG (1984) Neuropraxis secondary to hemorrhage in a traumatic dislocation of the shoulder. J Trauma 24:546-547

60. Battiston B, Vasario G, Marccocio I, Titolo P (2015) Traumatic brachial plexus injuries. In: Peretti G (ed) Neurologic shoulder, 1st edn. TIMEO Editore, Bologna, pp 57-65

61. Razif MA, Rajasingam V (2002) Anterior shoulder dislocation with axillary artery and nerve injury. Med J Malaysia 57:496-498

62. Emadian SM (1996) Axillary artery pseudoaneurysm and axillary nerve palsy: delayed sequelae of anterior shoulder dislocation. Am J Emerg Med 14:108-109

63. Helm AT, Watson JS (2002) Compression of the brachial plexus in a patient with false aneurysm of the axillary artery as a result of anterior shoulder dislocation. J Shoulder Elb Surg 11:278-279

64. Smania N, Berto G, La Marchina E, Melotti C, Midiri A, Roncari L et al (2012) Rehabilitation of brachial plexus injuries in adults and children. Eur J Phys Rehabil Med 48:483-506

65. Martinoli C, Bianchi S, Santacroce E, Pugliese F, Graif M, Derchi LE (2002) Brachial plexus sonography: a technique for assessing the root level. AJR Am J Roentgenol 179:699-702

66. Takase F, Inui A, Mifune Y, Muto T, Harada Y, Kokubu T et al (2014) Concurrent rotator cuff tear and axillary nerve palsy associated with anterior dislocation of the shoulder and large glenoid rim fracture: a "terrible tetrad". Case Rep Orthop 2014:312968. https://doi.org/10.1155/2014/312968

67. Brown TD, Newton PM, Steinmann SP, Levine WN, Bigliani LU (2000) Rotator cuff tears and associated nerve injuries. Orthopedics 23:329-332. https://doi.org/10.3928/0147-744720000401-14

68. Johnson SF, Johnson SB, Strodel WE, Barker DE, Kearney PA (1991) Brachial plexus injury: association with subclavian and axillary vascular trauma. J Trauma 31:1546-1550
69. Prudnikov OE (1994) Simultaneous lesions of the rotator cuff and the brachial plexus. Rev Chir Orthop Reparatrice Appar Mot 80: 602-609

70. Simonich SD, Wright TW (2003) Terrible triad of the shoulder. J Shoulder Elb Surg 12:366-368

71. Kline DG, Kim DH (2003) Axillary nerve repair in 99 patients with 101 stretch injuries. J Neurosurg 99:630-636

72. Zoltan JD (1979) Injury to the suprascapular nerve associated with anterior dislocation of the shoulder: case report and review of the literature. J Trauma 19:203-206

73. Bigliani LU, Dalsey RM, PD MC, April EW (1990) An anatomical study of the suprascapular nerve. Arthroscopy 6:301-305

74. Safran MR (2004) Nerve injury about the shoulder in athletes, part 1: suprascapular nerve and axillary nerve. Am J Sports Med 32: 803-819

75. Sunderland S (1978) Nerves and nerve injuries. Churchill Livingstone, Edinburgh

76. Burge P, Rushworth G, Watson N (1985) Patterns of injury to the terminal branches of the brachial plexus. The place for early exploration. J Bone J Surg Br 67:630-634

77. Lam WL, Fufa D, Chang NJ, Chuang DC (2015) Management of infraclavicular (Chuang Level IV) brachial plexus injuries: a single surgeon experience with 75 cases. J Hand Surg Eur 40:573582

78. Gutkowska O, Martynkiewicz J, Mizia S, Bąk M, Gosk J (2017) Results of operative treatment of brachial plexus injury resulting from shoulder dislocation: a study with a long-term follow-up. World Neurosurg 105:623-631. https://doi.org/10.1016/j.wneu. 2017.06.059

79. Gonzales D, Lopez R (1991) Concurrent rotator-cuff tear and brachial plexus palsy associated with anterior dislocation of the shoulder. J Bone Joint Surg Am 73:620-621

80. Güven O, Akbar Z, Yalçin S, Gündeș H (1994) Concomitant rotator cuff tear and brachial plexus injury in association with anterior shoulder dislocation: unhappy triad of the shoulder. J Orthop Trauma 8:429-430

81. Groh GI, Rockwood CA Jr (1995) The terrible triad: anterior dislocation of the shoulder associated with rupture of the rotator cuff and injury to the brachial plexus. J Shoulder Elb Surg 4:51-53

82. Johnson JR, Bayley JI (1982) Early complications of acute anterior dislocation of the shoulder in the middle-aged and elderly patient. Injury 13:431-434

83. Goubier JN, Duranthon LD, Vandenbussche E, Kakkar R, Augereau B (2004) Anterior dislocation of the shoulder with rotator cuff injury and brachial plexus palsy: a case report. J Shoulder Elb Surg 13:362-363. https://doi.org/10.1016/ S1058274603003161

84. Miller AG, Slenker N, Dodson CC (2012) Terrible triad of the shoulder in a competitive athlete. Am J Orthop (Belle Mead NJ) 41:228-229

85. Mehta MP, Kottamasu SR (1989) Anterior dislocation of the shoulders with bilateral brachial plexus injury. Ann Emerg Med 18:589-591

86. Coene LN, Narakas AO (1992) Operative management of lesions of the axillary nerve, isolated or combined with other nerve lesions. Clin Neurol Neurosurg 94(Suppl):S64-S66

87. Shin AY, Spinner RJ, Steinmann SP, Bishop AT (2005) Adult traumatic brachial plexus injuries. J Am Acad Orthop Surg 13: 382-396

88. Allie B, Kilroy DA, Riding G, Summers C (2005) Rupture of axillary artery and neuropraxis as complications of recurrent traumatic shoulder dislocation: case report. Eur J Emerg Med 12:121123

89. Nikolaou VS, Pilichou A, Staramos D, Chronopoulos E, Korres D, Efstathopoulos N (2008) Axillary artery and brachial plexus injury after anterior shoulder dislocation: report of a case and 
review of the literature. Eur J Orthop Surg Traumatol 18:595-598. https://doi.org/10.1007/s00590-008-0357-y

90. Mullett H, Babu J, McMahon B, Burke P (1998) Vascular complication of anterior dislocation of shoulder with associated brachial plexus injury — a case report. Ir J Med Sci 167:196

91. Mwipatayi BP, Finlayson A, Welman CJ, Hamilton MJ, Abbas M, Sieunarine K (2005) Axillary artery and brachial plexus injuries due to anterior shoulder dislocation. Eur J Trauma 31:181-185. https://doi.org/10.1007/s00068-005-1435-z

92. Curley SA, Osler T, Demarest GB (1988) Traumatic disruption of the subclavian artery and brachial plexus in a patient with EhlersDanlos syndrome. Ann Emerg Med 17:850-852

93. Shaw AD, Milne AA, Christie J, Jenkins AM, Murie JA, Ruckley CV (1995) Vascular trauma of the upper limb and associated nerve injuries. Injury 26:515-518

94. Chuang DC (2008) Brachial plexus reconstruction based on the new definition of level of injury. Injury 39S:S23-S29

95. Kim DH, Cho YJ, Tiel RL, Kline DG (2003) Outcomes of surgery in 1019 brachial plexus lesions treated at Louisiana State University Health Sciences Center. J Neurosurg 98:1005-1016. https://doi.org/10.3171/jns.2003.98.5.1005

96. Blum A, Lecocq S, Louis M, Wassel J, Moisei A, Teixeira P (2013) The nerves around the shoulder. Eur J Radiol 82:2-16. https://doi.org/10.1016/j.ejrad.2011.04.033

97. Kobayashi J, Mackinnon SE, Watanabe O, Ball DJ, Gu XM, Hunter DA, Kuzon WM Jr (1997) The effect of duration of muscle denervation on functional recovery in the rat model. Muscle Nerve 20:858-866

98. Fu SY, Gordon T (1995) Contributing factors to poor functional recovery after delayed nerve repair: prolonged denervation. J Neurosci 15:3886-3895

99. Kline DG (2009) Timing for brachial plexus injury: a personal experience. Neurosurg Clin N Am 20:24-26. https://doi.org/10. 1016/j.nec.2008.07.030

100. Hattori Y, Doi K, Sakamoto S, Yukata K (2009) Sensory recovery of the hand with intercostal nerve transfer following complete avulsion of the brachial plexus. Plast Reconstr Surg 123:276-283

101. Limthongthang R, Bachoura A, Songcharoen P, Osterman AL (2013) Adult brachial plexus injury: evaluation and management. Orthop Clin N Am 44:591-603. https://doi.org/10.1016/j.ocl. 2013.06.011

102. Kandenwein JA, Kretschmer T, Engelhardt M, Richter HP, Antoniadis G (2005) Surgical interventions for traumatic lesions of the brachial plexus: a retrospective study of 134 cases. J Neurosurg 103:614-621. https://doi.org/10.3171/jns.2005.103.4. 0614
103. Levy BA, Giuseffi SA, Bishop AT, Shin AY, Dahm DL, Stuart MJ (2010) Surgical treatment of peroneal nerve palsy after knee dislocation. Knee Surg Sports Traumatol Arthrosc 18:1583-1586. https://doi.org/10.1016/j.injury.2009.05.015

104. Kim DH, Murovic JA, Tiel RL, Kline DG (2004) Infraclavicular brachial plexus stretch injury. Neurosurg Focus 16(5):E4

105. Giuffre JL, Kakar S, Bishop AT, Spinner RJ, Shin AY (2010) Current concepts of the treatment of adult brachial plexus injuries. J Hand Surg [Am] 35:678-688. https://doi.org/10.1016/j.jhsa. 2010.01.021

106. Birch R (2011) Surgical disorders of the peripheral nerves. Springer, London

107. Chin CT (2014) Magnetic resonance neurography: brachial plexus. Proc Intl Soc Mag Reson Med 22:19

108. Du R, Auguste KI, Chin CT, Engstrom JW, Weinstein PR (2010) Magnetic resonance neurography for the evaluation of peripheral nerve, brachial plexus, and nerve root disorders. J Neurosurg 112: 362-371. https://doi.org/10.3171/2009.7.JNS09414

109. Beekman R, Visser LH (2004) High-resolution sonography of the peripheral nervous system - a review of the literature. Eur J Neurol 11:305-314

110. Shafighi M, Gurunluoglu R, Ninkovic M, Mallouhi A, Bodner G (2003) Ultrasonography for depiction of brachial plexus injury. J Ultrasound Med 22:631-634

111. Yoshikawa T, Hayashi N, Yamamoto S, Tajiri Y, Yoshioka N, Masumoto T et al (2006) Brachial plexus injury: clinical manifestations, conventional imaging findings and the latest imaging techniques. Radiographics 26(Suppl 1):S133-S143

112. Alnot JY (1988) Traumatic brachial plexus palsy in the adult. Retro- and infraclavicular lesions. Clin Orthop Relat Res 237:916

113. Solonen KA, Vastamäki M, Ström B (1984) Surgery of the brachial plexus. Acta Orthop Scand 55:436-440

114. Terzis JK, Barmpitsioti A (2010) Axillary nerve reconstruction in 176 posttraumatic plexopathy patients. Plast Reconstr Surg 125: 233-247. https://doi.org/10.1097/PRS.0b013e3181c496e4

115. Terzis JK, Kostopoulos VK (2007) The surgical treatment of brachial plexus injuries in adults. Plast Reconstr Surg 119:73-92

116. Terzis JK, Vekris MD, Soucacos PN (1999) Outcomes of brachial plexus reconstruction in 204 patients with devastating paralysis. Plast Reconstr Surg 104:1221-1240

117. Williams FH, Kumiga B (2013) Less common upper limb mononeuropathies. PM R 5(5 Suppl):22-30. https://doi.org/10. 1016/j.pmrj.2013.03.021

118. Kretchmer T, Ihle S, Antoniadis G, Seidel J, Heinen C, Börm W, Richter HP, König R (2009) Patient satisfaction and disability after brachial plexus injury. Neurosurgery 65(4 Suppl):189-196 